REVIEW ARTICLE

\title{
AN OVER VIEW ON STEM CELL AS A GENETIC MEDICINE
}

\author{
Anish K Gupta \\ Micro Labs Ltd, Baddi, District- Solon, Himachal Pradesh, INDIA \\ Author's Email: anishpharma02@rediffmail.com
}

Received 20 Jan 2012; Revised 17 Feb 2012; Accepted 01 March 2012, Available online 15 March 2012

\begin{abstract}
Stem cell treatments are a type of genetic medicine that introduces new cells into damaged tissue in order to treat a disease or injury. A number of stem cell treatments exist, although most are still experimental and/or costly, with the notable exception of bone marrow transplantation. Stem cells are a unique and important set of cells that are not specialized. Stem cells retain the ability to become many or all of the different cell types in the body and thereby play a critical role in repairing organs and body tissues throughout life. Stem cells provide the opport unity to study the growth and differentiation of individual cells into tissues. For over 30 years, bone marrow, and more recently, umbilical cord blood stem cells have been used to treat cancer patients with conditions such as leukemia and lymphoma. Understanding these processes could provide insights into the causes of birth defects, genetic abnormalities, and other disease states.
\end{abstract}

Keywords: Stem cell, gen etic medicine, human embry o, leukaemia

\section{INTRODUCTION}

Stem cell treatments are a type of genetic medicine that introduces new cells into damaged tissue in order to treat a disease or injury. Many medical researchers believe that stem cell treatments have the potential to change the face of human disease and alleviate suffering. The ability of stem cells to self-renew and give rise to subsequent generations that can differentiate ${ }^{1}$ offers a large potential to culture tissues that can replace diseased and damaged tissues in the body, without the risk of rejection and side effects.

A number of stem cell treatments exist, although most are still experimental and/or costly, with the notable exception of bone marrow transplantation. Medical researchers anticipate one day being able to use technologies derived from adult and embryonic stem cell research to treat cancer, Type 1 diabetes mellitus, Parkinson's disease, Huntington's disease, Celiac Disease, cardiac failure, muscle damage and neurological disorders, along with many others. ${ }^{2}$

Stem cell research holds great promise for improving human health by control of degenerative diseases and restoration of damage to organs by various injuries; but at the same time it also raises several ethical and social is sues such as destruction of human embryos to create human embryonic stem (hES) cell lines, potential for introducing commodification in human tissues and organs with inherent barriers of access to socioeconomically deprived and possible use of technology for germ-line engineering and reproductive cloning. The research in this field, therefore, needs to be regulated to strike a balance.
Of utmost importance is assurance of safety and rights of those donating gametes/ blastocysts/ somatic cells for derivation of stem cells; or fetal tissues/umbilical cord cells/ adult tissue (or cells) for use as stem cells. Safeguards have also to be in place to protect research participants receiving stem cell transplants, and patients at large from unproven therapies/remedies. With success of growing human embryonic stem cells without feeder layer, derivation of histocompatible hES from embryos created by Somatic Cell Nuclear Transfer (SCNT) and tissue specific differentiation of umbilical cord/bone marrow derived mesenchymal and haematopoeitic stem cells, there is a need to generate public confidence in potential benefit of stem cell research to human health and disease. As stem cell therapy is poised to enter into clinical practice, there is an urgent need to formulate guidelines for Stem cell Research and Therapy (SCRT). ${ }^{3}$

\section{OVERVIEW OF BAS IC RES EARCH}

Most cells within an animal or human being are committed to fulfilling a single function within the body. In contrast, stem cells are a unique and important set of cells that are not specialized. Stem cells retain the ability to become many or all of the different cell types in the body and thereby play a critical role in repairing organs and body tissues throughout life. Although the term stem cells is often used in reference to these repair cells within an adult organism, a more fundamental variety of stem cells is found in the early stage embryo. Embryonic stem cells may have a greater ability to become different types of body cells than adult stem cells. ${ }^{4}$ 


\section{Stem Cells from Embryos or Fetal Tissue}

Embryonic stem cells were first isolated from mouse embryos in 1981. Animal embryos were the only source for research on embryonic stem cells until November 1998, when two groups of U.S. scientists announced the successful isolation of human embryonic stem cells. One group, at the University of Wisconsin, derived stem cells from one-week-old embryos produced via in vitro fertilization (IVF). 1 The work is controversial, in the opinion of some individuals, because the stem cells are located within the embryo and the process of removing them destroys the embryo. The second group, at Johns Hopkins University, derived cells with very similar properties from five- to nineweek- old embryos or foetuses obtained through elective abortion. ${ }^{2}$ Both groups reported the human embryos or foetuses were donated for research following a process of informed consent. The cells were then manipulated in the laboratory to create embryonic stem cell lines that may continue to divide for many months to years. Another potential source of embryonic stem cells is somatic cell nuclear transfer (SCNT), also referred to as cloning. 3 In SCNT the nucleus of an egg is removed and replaced by the nucleus from a mature body cell, such as a skin cell. The cell created via SCNT is allowed to develop for a week and then the stem cells are removed. In 1996, scientists in Scotland used the SCNT procedure to produce Dolly the sheep, the first mammalian clone.4 In February 2004, Korean scientists announced that they had created human embryos via the SCNT process and had succeeded in isolating human stem cells from a cloned embryo. This development and the unsubstantiated announcement by Clonaid in December 2002 of the birth of a cloned child have contributed to the controversy over research on human embryos.

\section{Stem Cells from Adult Tissue or Umbilical Cord Blood}

Stem cells obtained from adult organisms are also the focus of research. There have been a number of recent publications on adult stem cells from a variety of different sources, such as bone marrow and the umbilical cord following birth. In addition, a number of private companies (such as MorphoGen, NeuralStem, Osiris Therapeutics, Stem Source, ViaCell) are working on therapeutic uses of adult stem cells. Some advocate that adult instead of embryonic stem cell research should be pursued because they believe the derivation of stem cells from either IVF embryos or aborted foetuses is ethically unacceptable. Others believe that adult stem cells should not be the sole target of research because of important scientific and technical limitations. Adult stem cells may not be as long lived or capable of as many cell divisions as embryonic stem cells. Also, adult stem cells may not be as versatile in developing into various types of tissue as embryonic stem cells, and the location and rarity of the cells in the body might rule out safe and easy access. For these reasons, many scientists argue that both adult and embryonic stem cells should be the subject of research, allowing for a comparison of their various capabilities.

\section{Classification of human stem cells ${ }^{6}$}

On the basis of their orig in three groups of stem cells are recognized:
A. Hu man embryonic stem (hES) cells, derived from blastocysts:

a) Blastocysts derived from surplus embryos from IVF clinics.

b) Blastocysts derived specifically for research or therapy using IVF.

c) Blastocysts derived by other techniques like SCNT etc.

B. Hu man embryonic germ (hEG) cells, which are derived from primo rdial germ cells of the foetus.

D. Hu man somatic stem (hSS) cells, which are derived from fetal or adult tissues or organs, including umbilical cord blood / placenta.

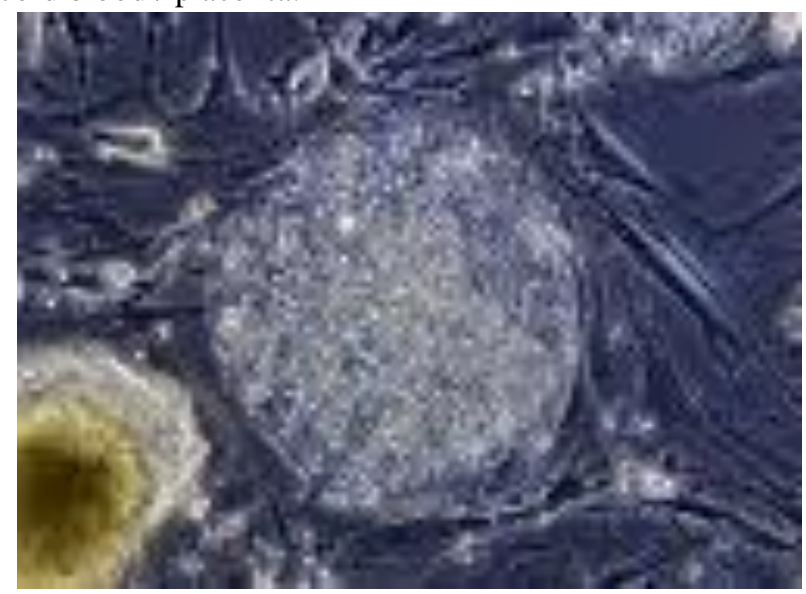

Figure 1: A Human Stem Cell

\section{SOURCES AND CHARACTERIS TICS OF HUMAN STEM CELLS}

Human Embryonic Stem Cells: The study of human stem cells has barely begun and what is known is summarized in this section. The vast majority of experimental data discussed here are the results of experiments in mice. ES cells from the mouse have been intensely investigated since their discovery 18 years ago. Therefore, what is said about human ES cells assumes in part that their fundamental properties will resemble those of mouse ES cells. While on the surface this assumption appears to be reasonable it will have to be proven through intensive further investigation. There is an abundance of stem cell lines from mammals including some from human beings. ES cells are valuable scientifically because they combine three properties not found together in other cell lines. First, they appear to replicate indefinitely without undergoing senescence (aging and death) or mutation of the genetic material. They are thus a large-scale and valuable source of cells. Second, ES cells appear genetically normal, both by a series of genetic tests and functionally as shown by the creation of mice with genomes derived entirely from ES cells. In mice these cells are developmentally totipotent; when inserted into an early embryo, they join the host cells to create a normal mouse, differentiating into every cell type of the body (it is this property that earns them the name "stem cell of the body"). ES cells can also differentiate into many cell types in tissue culture, including neurons, blood cells and cardiac and skeletal 
muscle. The normal embryo has about 100 cells with the properties of ES cells that exist for about one day and then develop into more advanced cell types. The isolation and subsequent growth of ES cells in culture allow scientists to obtain millions of these cells in a single tissue culture flask, making something once rare and precious now readily available to researchers. It is worth noting here the striking parallel to recombinant DNA and monoclonal antibody technologies, both of which have amplified rare and precious biological entities. Like those technologies, ES cell technology may well be transformative in opening scientific arenas that to date have been closed.

The isolation, culture, and partial characterization of stem cells isolated from human embryos was reported in November of $1998 .^{7}$ The ability of the cells to maintain their pluripotent character even after 4 to 5 months of culturing was demonstrated.2 There is concern that this feature of these cells could also lead to cancerous growth. Thus far there are no data indicating the induction of malignant tumours, although there is some evidence for benign hyper proliferation (overgrowth of cells). ${ }^{8}$

\section{Human Embryonic Germ Cells:}

Embryonic germ cells are derived from primordial germline cells in early foetal tissue during a narrow window of development. Unlike embryonic stem cells, animal experiments on embryonic germ cells have been limited. In November of 1998, the isolation, culture, and partial characterization of germ cells derived from the gonadal ridge of human tissue obtained from abortuses was reported. ${ }^{9}$ These experiments showed that these EG cells are capable of forming the three germ layers that make all the specific organs of the body. There are fewer data from animal EG cell experiments than from ES cell experiments, but it is generally assumed that the range of potential fates will be relatively limited compared to ES cells, because the EG cells are much further along in development (5-9 weeks as opposed to 5 days in the published experiments). Foetal tissue may provide committed neural progenitors, but the feasibility of large scale sourcing and manufacturing of products utilizing such cells is questionable. Furthermore, the behaviour of these cells in vivo is not well understood; significant research will be required to avoid unwanted outcomes, including ectopic tissue formation (additional, unwanted tissue), tumor induction, or other abnormal development. ${ }^{10}$

\section{Human adult stem cells}

From post-embryonic development through the normal life of any organism, certain tissues of the body require stem cells for normal turnover and repair. Stem cells that are found in developed tissue, regardless of the age of the organism at the time, are referred to as adult stem cells (Fig. 1). The most well-known example of this are the hematopoietic stem cells of blood. ${ }^{11}$ More recently, mesenchymal stem cells (MSC) required for the maintenance of bone, muscle, and other tissues have beendiscovered. ${ }^{12}$ Adult stem cells are multipotent; the number of tissues that they can regenerate compares poorly with the pluripotency of embryonic stem cells and embryonic germ cells. However, the MSC is in fact an excellent example of the potential for use of stem cells in human therapeutic procedures. MSCs are capable of differentiating into bone, cartilage, muscle, fat, and a few other tissue types. Their use for bone and cartilage replacement is undergoing FDA-approved clinical trials at the present

time.

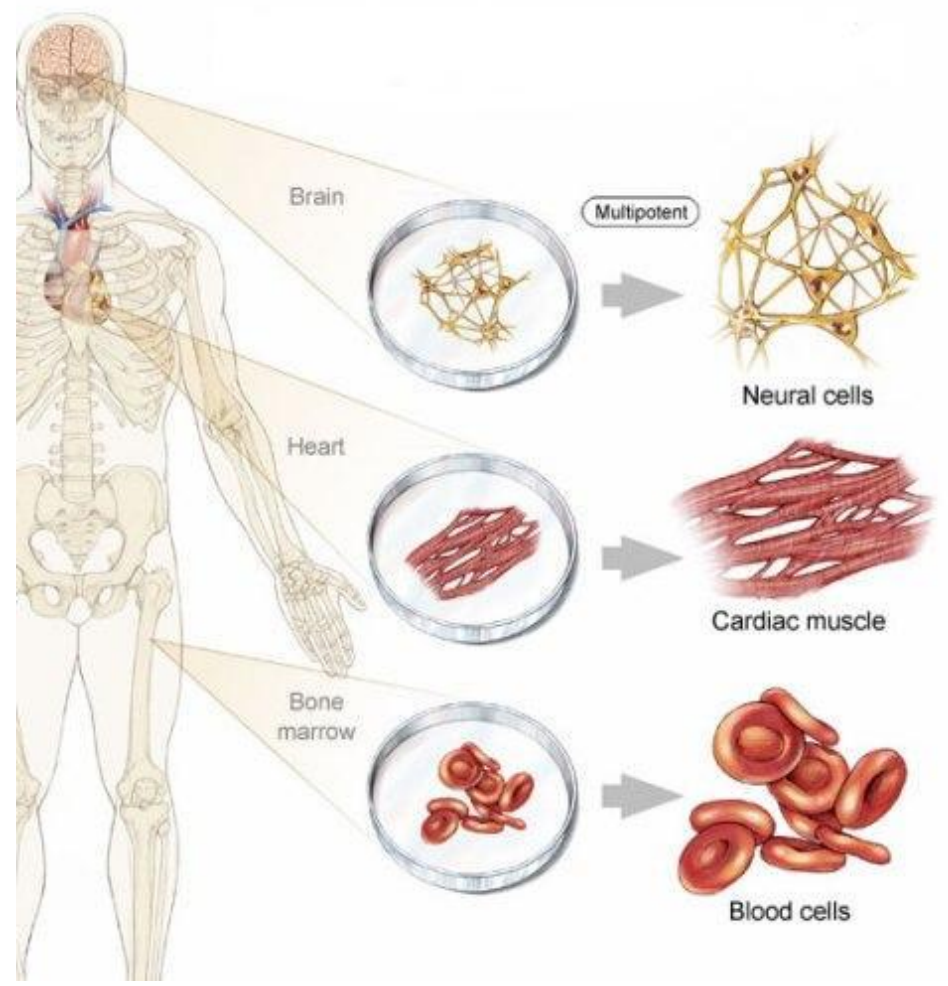

Figure 2: Multipotent Stem Cells 
Adult-derived stem cell therapies will complement, but cannot replace, therapies that may be eventually obtained from ES cells. They do have some advantages. For example, adult stem cells offer the opportunity to utilize small samples of adult tissues to obtain an initial culture of a patient's own cells for expansion and subsequent implantation (this is called an autologous transplant). This process avoids any ethical or legal issues concerning sourcing, and also protects the patient from viral, bacterial, or other contamination from another individual. With proper manufacturing quality controls and testing, allogeneic adult stem cells (cells from a donor) may be practical as well. Already in clinical use are autologous and allogeneic transplants of hematopoietic stem cells that are isolated from mobilized peripheral blood or from bone marrow by positive selection with antibodies in commercial devices. In general, there is less ethical concern over their initial source. Additionally, since they normally differentiate into a narrower set of cell types, directing them to a desired fate is more straightforward. However, many cells of medical interest cannot, as of yet, be obtained from adult-derived cell types. Production of large numbers of these cells is much more difficult than is the case for ES cells. Based upon our present knowledge base, it appears unlikely that human adult stem cells alone will provide the entire necessary cell types required for the most clinically important areas of research.

\section{Possible Sources of Stem Cells}

$>$ Embryos created via IVF (for infert ility treat ment or for research purposes)

$>$ Embryos or foetuses obtained through elective abortion

$>$ Embryos created via SCNT (somatic cell nuclear transfer, or cloning)

$>$ Adult tissues (bone marrow, u mbilical cord blood)

\section{Spiritual and Religious Contexts}

Two broad and somewhat opposing themes characterize the response of most religious communities and traditions to the promising new biomedical technology that stem cell research represents. On the one hand, there is a moral commitment to healing and to relieving suffering caused by injury and illness. For biblically-based traditions, this commitment reflects a responsibility to serve as partners with God and stewards of God's creation. Because of this commitment, most religious communities applaud the promise of stem cell research for enhancing scientific understanding of human development; for probing the cellular origins of cancer, diabetes, spinal cord injury, arthritis, and a host of other lethal or disabling illnesses and conditions; for developing more effective pharmacological drugs; and for pursuing successful tissue and organ transplant technology. On the other hand, most traditions also warn that human beings are not God. Humans lack omniscience and our pursuits are often tainted by selfishness. With regard to stem cell research, this suggests the need to be cautious in pursuing the promise of this research and to strive to anticipate and minimize its potential harms and misuses. These include direct harms to the donors of the tissues and embryos from which stem cells may be derived and harms to future research subjects exposed to the unknown risks of stem cell implants. It also includes possible longer-term harms to society ranging from damage to our respect for the sanctity of human life to inequities resulting from the appropriation or privatization of a resource with great potential to benefit everyone.

Beyond these two broadly shared themes, there is significant disagreement among American religious communities over some of the specific moral is sues raised by stem cell research. The most medically promising stem cells, with a capacity to differentiate into any of the human body's cell types, are derived either from the inner cell mass of pre-implantation embryos (ES cells) or from the gonadal tissue of aborted foetuses (EG lls). Both of these sources involve extraction and manipulation of cells from human embryos or foetuses. This raises issues of fundamental importance for some religious communities and can profoundly engage the conscience of Americans. There are two principal areas of disagreement. One concerns the question of whether it is ever morally appropriate to destroy an embryo and whether the benefits of research provide a justification for doing so. At issue here is the question of whether the human embryo (or foetus in the case of EG cells) possesses significant moral status and must be protected from harm. A mong those who answer this in the affirmative, a second question and some further disagree ments arise. This is the question of whether researchers who have played no part in the destruction of an embryo or fetus may ethically utilize cellular materials produced in these ways. This is the question of when, if ever, it is morally permissible to cooperate with or benefit from what some persons regard as evil acts. The first of these questions is among the most controversial in our society. Some religious communities believe the embryo or fetus is a full human being from the moment of

conception, since it is genetically human and has the potential for development into a human individual.15 Other traditions take a "developmental" view of personhood, believing that the early embryo or foetus only gradually becomes a full human being and thus may not be entitled to the same moral protections as it will later.16 Still others hold that while the embryo represents human life, that life may be taken for the sake of saving and preserving other lives in the future. 17

It is noteworthy that, despite these differences, all these positions can support research that does not involve the use of embryonic or fetal cells, that is to say, adult stem cell research. Opponents of abortion also support the use of foetal tissues when these result from stillbirths or miscarriages. They object only to the deliberate destruction of foetuses or embryos. Unfortunately, these zones of agreement do not include some promising areas of stem cell research, those involving the use of cells obtained from embryos (ES cells), or from deliberately aborted foetuses (EG cells). The fact that much basic research needs to be done in the area of human embryonic development suggests that both ES and EG cells will continue to play an important role in future research endeavours. Where germ cells are concerned, spontaneous abortions or stillbirths are a poor source of the tissue, both because the collection of the tis sue requires substantial 
preparation, the critical time period is of short duration, and because, with spontaneous abortions particularly, this tis sue is likely to suffer from genetic abnormalities. While continuing research efforts must be made to understand the biology of alternative sources of such cells, adult stem cells cannot entirely replace either EG and ES cells because much basic research needs to be done in the area of early human embryonic development for which EG and ES cells are required.

The zone of agreement is somewhat widened, however, when we recognize that some who adamantly oppose the destruction of embryos or foetuses can accept the view that research on the cellular materials remaining from such acts is not always unethical. These individuals take the view that not all acts benefiting from others' wrongdoing are morally impermissible, so long as one is not in any way involved in the wrongdoing and one's own acts do not foster, encourage, or lend support to it. For some who hold this moral position, no involvement with foetal or embryo destruction can meet this test, as all such involvement amounts to wrongful cooperation with evil.18 However, others equally opposed to embryo destruction may conclude differently. 19

Despite the possibility of achieving some consensus in these directions, important disagreements remain. Some who hold the view that full moral protection begins at conception will conclude that their religious and ethical perspective requires them to oppose any federal involvement in stem cell research so long as embryo or foetal destruction is involved, and they may even believe that all activities of this sort should be prohibited. Others, drawing on their own religious beliefs, will determine that stem cell research is not only ethically permitted, but required in the name of promoting human health.

\section{POTENTIAL APPLICATIONS OF STEM CELL RESEARCH. ${ }^{14}$}

Stem cells provide the opportunity to study the growth and differentiation of individual cells into tissues. Understanding these processes could provide insights into the causes of birth defects, genetic abnormalities, and other disease states. If normal development were better understood, it might be possible to prevent or correct some of these conditions. Stem cells could be used to produce large amounts of one cell type to test new drugs for effectiveness and chemicals for toxicity. Stem cells might be transplanted into the body to treat disease (diabetes, Parkinson's disease) or injury (e.g., spinal cord). The damaging side effects of medical treatments might be repaired with stem cell treatment. For example, cancer chemotherapy destroys immune cells in patients, decreasing their ability to fight off a broad range of diseases; correcting this adverse effect would be a major advance.

Before stem cells can be applied to human medical problems, substantial advances in basic cell biology and clinical technique are required. In addition, very challenging regulatory decisions will be required on the individually created tissue based therapies resulting from stem cell research. Such decisions would likely be made by the Center for Biologics Evaluation and Research
(CBER) of the Food and Drug Administration (FDA). The potential benefits mentioned above would be likely only after many more years of research. Technical hurdles include developing the ability to control the differentiation of stem cells into a desired cell type (like a heart or nerve cell) and to ensure that uncontrolled development, such as a cancerous tumor, does not occur. If stem cells are to be used for transplantation, the problem of immune rejection must also be overcome. Some scientists think that the creation of many more embryonic stem cell lines will eventually account for all the various immunological types needed for use in tissue transplantation therapy. Others envision the eventual development of a "universal donor" type of stem cell tissue, analogous to a universal blood donor.

However, if the SCNT technique (cloning) was employed using a cell nucleus from the patient, stem cells created via this method would be genetically identical to the patient, would presumably be recognized by the patient's immune system, and thus would avoid any tissue rejection problems that could occur in other stem cell therapeutic approaches. Because of this, many scientists believe that the SCNT technique may provide the best hope of eventually treating patients using stem cells for tissue transplantation.

\section{APPLICATIONS OF STEM CELLS IN TREATMENT OF DES EAS ES :}

\section{Brain damage}

Stroke and traumatic brain injury lead to cell death, characterized by a loss of neurons and ligodendrocytes within the brain. Healthy adult brains contain neural stem cells which divide and to maintain general stem cell numbers, or become progenitor cells. In healthy adult animals, progenitor cells migrate within the brain and function primarily to maintain neuron populations for olfaction (the sense of smell). Interestingly, in pregnancy and after injury, this system appears to be regulated by growth factors and can increase the rate at which new brain matter is formed. In the case of brain in jury, although the reparative process appears to initiate, substantial recovery is rarely observed in adults, suggesting a lack of robustness. Stem cells may also be used to treat brain degeneration, such as in Parkinson's and Alzheimer's disease. $^{15,16}$

\section{Cancer}

Research injecting neural (adult) stem cells into the brains of dogs has shown to be very successful in treating cancerous tumors. With traditional techniques brain cancer is almost impossible to treat because it spreads so rapidly. Researchers at the Harvard Medical School induced intracranial tumours in rodents. Then, they injected human neural stem cells. Within days the cells had migrated into the cancerous area and produced cytosine deaminase, an enzyme that converts a non-toxic pro-drug into a chemotheraputic agent. As a result, the injected substance was able to reduce tumor mass by 81 percent. The stem cells neither differentiated nor turned tumorigenic. ${ }^{17}$ Some researchers believe that the key to finding a cure for cancer is to inhibit cancer stem cells, where the cancer tumor 
originates. Currently, cancer treatments are designed to kill all cancer cells, but through this method, researchers would be able to develop drugs to specifically target these stem cells. $^{18}$

\section{Spinal cord injury}

A team of Korean researchers reported on November 25, 2003, that they had transplanted multipotent adult stem cells from an umbilical cord blood to a patient suffering from a spinal cord injury and that she can now walk on her own, without difficulty. The patient had not been able to stand up for roughly 19 years. For the unprecedented clinical test, the scientists isolated adult stem cells from umbilical cord blood and then injected them into the damaged part of the spinal cord. ${ }^{19}[20$

According to the October 7, 2005 issue of The Week, University of California researchers injected human embryonic stem cells into paralyzed mice, which resulted in the mice regaining the ability to move and walk four months later. The researchers discovered upon dissecting the mice that the stem cells regenerated not only the neurons, but also the cells of the myelin sheath, a layer of cells which insulates neural impulses and speeds them up, facilitating communication with the brain (damage to which is often the cause of neurological injury in humans).

In January 2005, researchers at the University of Wiscons in-Madison differentiated human blastocyst stem cells into neural stem cells, then into the beginnings of motor neurons, and finally into spinal motor neuron cells, the cell type that, in the human body, transmits messages from the brain to the spinal cord. The newly generated motor neurons exhibited electrical activity, the signature action of neurons. Lead researcher Su-Chun Zhang described the process as "you need to teach the blastocyst stem cells to change step by step, where each step has different conditions and a strict window of time."

Transforming blastocyst stem cells into motor neurons had eluded researchers for decades. The next step will be to test if the newly generated neurons can communicate with other cells when transplanted into a living animal; the first test will be in chicken embryos. Su-Chun said their trialand-error study helped them learn how motor neuron cells, which are key to the nervous system, develop in the first place. The new cells could be used to treat diseases like Lou Gehrig's disease, muscular dystrophy, and spinal cord injuries.

\section{Heart damage}

Several clinical trials targeting heart disease have shown that adult stem cell therapy is safe and effective, and is equally efficient in old as well as recent infarcts. ${ }^{21}$ Adult stem cell therapy for heart disease was commercially available on at least five continents at the last count (2007).

Possible mechanis ms are: ${ }^{15}$

- Generation of heart muscle cells

- Stimulation of growth of new blood vessels that repopulate the heart tissue
- Secretion of growth factors, rather than actually incorporating into the heart

- Assistance via some other mechanism

It may be possible to have adult bone marrow cells differentiate into heart muscle cells. ${ }^{[15]}$

\section{Haematopoiesis (blood cell formation)}

The specificity of the human immune cell repertoire is what allows the human body to defend itself from rapidly adapting antigens. However, this system is a hot spot for degradation upon the pathogenesis of disease, and because of the critical role that it plays in organismal defense, its degradation is often fatal to the system as a whole. Diseases of hematopoietic cells are called hematopathology. The specificity of the immune cells is what allows them to recognize foreign antigens, causing further challenges in the treatment of immune disease. Identical matches between donor and recipient must be made for successful transplantation treatments, while matches are uncommon, even between first-degree relatives. Research using both hematopoietic adult stem cells and embryonic stem cells has contributed great insight into possible mechanisms and methods of treatment for many of these ailments.

Fully mature human red blood cells may be generated ex vivo by hematopoietic stem cells (HSCs), which are precursors of red blood cells. In this process, HSCs are grown together with stromal cells, creating an environment that mimics the conditions of bone marrow, the natural site of red blood cell growth. Erythropoietin, a growth factor, is added, coaxing the stem cells to complete terminal diffe rentiation into red blood cells. ${ }^{22}$ Further research into this technique should have potential benefits to gene therapy, blood transfusion, and topical medicine.

\section{Bal dness}

Hair follicles also contain stem cells, and some researchers predict research on these follicle stem cells may lead to successes in treating baldness through "hair multiplication", also known as "hair cloning". This treatment is expected to work through taking stem cells from existing follicles, multiply ing them in cultures, and implanting the new follicles into the scalp. Later treatments may be able to simply signal follicle stem cells to give off chemical signals to nearby follicle cells which have shrunk during the aging process, which in turn respond to these signals by regenerating and once again making healthy hair. ${ }^{23}$

\section{Missing teeth}

In 2004, scientists at King's College London discovered a way to cultivate a complete tooth in mice ${ }^{24}$ and were able to grow them stand-alone in the laboratory. Researchers are confident that this technology can be used to grow live teeth in human patients.

In theory, stem cells taken from the patient could be coaxed in the lab into turning into a tooth bud which, when implanted in the gums, will give rise to a new tooth, which would be expected to take two months to grow. ${ }^{25}$ It will fuse with the jawbone and release chemicals that 
encourage nerves and blood vessels to connect with it. The process is similar to what happens when humans grow their original adult teeth. Many challenges remain, however, before stem cells could be a choice for the replacement of missing teeth in the future. ${ }^{26}$

\section{Deafness}

There has been success in re-growing cochlea hair cells with the use of stem cells. ${ }^{27}$

\section{Blindness and vision impairment}

Since 2003, researchers have successfully transplanted retinal stem cells into damaged eyes to restore vision. Using embryonic stem cells, scientists are able to grow a thin sheet of totipotent stem cells in the laboratory. When these sheets are transplanted over the damaged retina, the stem cells stimulate renewed repair, eventually restoring vision. ${ }^{28}$ The latest such development was in June 2005, when researchers at the Queen Victoria Hospital of Sussex, England were able to restore the sight of forty patients using the same technique. The group, led by Dr. Sheraz Daya, was able to successfully use adult stem cells obtained from the patient, a relative, or even a cadaver. Further rounds of trials are ongoing. ${ }^{29}$

In April 2005, doctors in the UK transplanted corneal stem cells from an organ donor to the cornea of Deborah Catlyn, a woman who was blinded in one eye when an acid was thrown in her eye at a nightclub. The cornea, which is the transparent window of the eye, is a particularly suitable site for transplants. In fact, the first successful human transplant was a cornea transplant. The cornea has the remarkable property that it does not contain any blood vessels, making it relatively easy to transplant. The majority of corneal transplants carried out today are due to a degenerative disease called keratoconus.

The University Hospital of New Jersey claims a success rate growing the new cells from transplanted stem cells varies from 25 percent to 70 percent. ${ }^{30}$ In 2009 , researchers at the University of Pittsburgh Medical center demonstrated that stem cells collected from human corneas can restore transparency without provoking a rejection response in mice with corneal damage. ${ }^{[31]}$

\section{Amyotrophic lateral sclerosis}

Stem cells have cured rats with an Amyotrophic lateral sclerosis-like disease. The rats were injected with a virus to kill the spinal cord motor nerves related to leg movement, succeeded by injections of stem cells into their spinal cords. These migrated (passed through many layers of tissues) to the sites of injury where they were able to regenerate the dead nerve cells restoring the rats which were once again able to walk. ${ }^{32}$

\section{Graft vs. host disease and Crohn's disease}

Phase III clinical trials expected to end in second-quarter 2008 were conducted by Osiris Therapeutics using their indevelopment product Prochymal, derived from adult bone marrow. The target disorders of this therapeutic are graftversus-host disease and Crohn's disease. ${ }^{33}$

Neural and behavioral birth defects
A team of researchers led by Prof. Joseph Yanai were able to reverse learning deficits in the offspring of pregnant mice who were exposed to heroin and the pesticide organophosphate. This was done by direct neural stem cell transplantation into the brains of the offspring. The recovery was almost 100 percent, as proved in behavioral tests in which the treated animals improved to normal behavior and learning scores after the transplantation. On the molecular level, brain chemistry of the treated animals was also restored to normal. Through the work, which was supported by the US National Institutes of Health, the USIsrael Binational Science Foundation and the Israel antidrug authorities, the researchers discovered that the stem cells worked even in cases where most of the cells died out in the host brain.

The scientists found that before they die the neural stem cells succeed in inducing the host brain to produce large numbers of stem cells which repair the damage. These findings, which answered a major question in the stem cell research community, were published earlier this year in the leading journal, Molecular Psychiatry. Scientists are now developing procedures to administer the neural stem cells in the least invasive way possible - probably via blood vessels, making therapy practical and clinically feasible. Researchers also plan to work on developing methods to take cells from the patient's own body, turn them into stem cells, and then transplant them back into the patient's blood via the blood stream. Aside from decreasing the chances of immunological rejection, the approach will also eliminate the controversial ethical issues involved in the use of stem cells from human embryos..$^{34}$

\section{Diabetes}

Diabetes patients lose the function of their insulinproducing beta cells of their pancreas. Human embryonic stem cells may be grown in cell culture and stimulated to form insulin-producing cells that can be transplanted into the patient.

However, success depends on developing procedures in all required steps: ${ }^{15}$

- Have the cells proliferate and generate sufficient amount of tissue

- Differentiation into the right cell type

- Survival of the cells in the recipient (prevention of transplant rejection)

- Integration with the surrounding tissue in the body

- Function appropriately in long-term

\section{Orthopedics}

Clinical case reports in the treatment of orthopedic conditions have been reported. To date, the focus in the literature for musculoskeletal care appears to be on mesenchymal stem cells. Centeno et al. have published MRI evidence of increased cartilage and meniscus volume in individual human subjects. ${ }^{35}{ }^{36}$ The results of trials including more patients are yet to be published making it hard to extrapolate the generalizability of these case reports. A newly published safety study published by the 
same group shows good safety and fewer complications than surgical care in a large study group of 227 patients over a 3-4 year period. ${ }^{15}$ Wakitani has also published a small case series of nine defects in five knees involving surgical transplantation of mesenchymal stem cells with coverage of the treated chondral defects. ${ }^{37}$

\section{Wound healing}

In one experimental method in regenerative medicine, stem cells are used to stimulate the growth of human tissues. In an adult, wounded tissue is most often replaced by scar tissue, which is characterized in the skin by disorganized collagen structure, loss of hair follicles and irregular vascular structure. In the case of wounded fetal tissue, however, wounded tissue is replaced with normal tissue through the activity of stem cells. ${ }^{38} \mathrm{~A}$ possible method for tissue regeneration in adults is to place adult

\section{REFERENCES :}

1. Gurtner GC, Callaghan, MJ and Longaker MT. Progress and Potential for Regenerative Medicine. Annu. Rev. Med 58:299-312, 2007.

2. Singec I, Jandial R, Crain A, Nikkhah G and Snyder EY. The leading ed ge of stem cell therapeutics. Annu. Rev. Med. 58: 313-328, 2007.

3. Guidelines for stem cell research and therapy, Director General, Indian Council of Medical Research, New Delhi, Nov. 2007 p. 1

4. Judith A. Johnson, Erin Williams, Stem Cell Research, CRS Report for Congress, August 13, 2004 pg.1

5. Judith A. Johnson, Erin Williams, Stem Cell Research, CRS Report for Congress, August 13, 2004 pg.1-2

6. Guidelines for stem cell research and therapy Director General Indian Council of Medical Research, New Delhi, Nov. 2007 p.3

7. Thomson JA, Waknitz MA, Swiergiel JJ, Marshall VS, "Embryonic Stem Cell Lines Derived from Human Blastocy sts." Science, 282: 1061-1062 (1998).

8. Thomas Okarma (Geron Corporation), AAAS Public Forum on Stem Cell Research Issues (25 August 1999.

9. Shamblott MJ, Axelman J, Wang S, Bugg EM, Littlefield, JW, Donovan PJ,

Blumenthal PD, Huggins GR, and Gearh art JD. "Derivation of Pluripotent Stem

Cells from Cultured Human Primordial Germ Cells. “

Proceedings of the National

Academy of Sciences, 95: 13726-13731 (1998).

10. Kato Y, Rideout WM, Hilton K, Barton SC, Tsunoda Y., and Surani MA. "Developmental potential of mouse primordial germ cells." Development 126: 1823-1832 99).

11. http://oncolink.upenn.edu and http://www.fhcrc.org.

12. Pittenger MF, Mackay AM, Beck SC, Jaiswal RK, Douglas, $\mathrm{R}$, Mosca $\mathrm{J}$,

Moorman M, Simonetti D, Craig S, and Marshak DR, "Multilineage Potential of

Mesenchy mal Stem Cells." Science, 284: 143-147 (1999).

13. Audrey R. Chapman MS. Frankel MS. Stem Cell Research and Applications November 1999 p.8-10

14. Judith A. Johnson Erin Williams Stem Cell Research August 13,2004 p.2-3

15. Bethesda MD: National Institutes of Health, U.S. Department of Health and Human Services, 2009. cited Sunday, April 26, 2009

16. http://www.sciencedaily.com/releases/2009/07/0907201907 26.htm stem cell "seeds" inside a tissue bed "soil" in a wound bed and allow the stem cells to stimulate differentiation in the tissue bed cells. This method elicits a regenerative response more similar to fetal wound-healing than adult scar tissue formation. Researchers are still investigating different aspects of the "soil" tissue that are conducive to regeneration. ${ }^{38}$

\section{Infertility}

Culture of human embryonic stem cells in mitotically inactivated porcine ovarian fibroblasts (POF) causes differentiation into germ cells (precursor cells of oocytes and spermatozoa), as evidenced by gene expression analysis. ${ }^{39}$ Human embryonic stem cells have been stimulated to form Spermatozoon-like cells, yet still slightly damaged or malformed. ${ }^{40}$ It could potentially treat azoospermia.

17. Douglas Steinberg Stem Cells Tapped to Replenish Organs thescientist.com, Nov 2000.

18. "Cancer Stem Cells Hint at Cure" at wired.com

19. Kang KS, Kim SW, Oh YH, et al. "A 37-year-old spinal cord-injured female patient, transplanted of multipotent stem cells from human UC blood, with improved sensory perception and mobility, both functionally and morphologically: a case study". Cytotherapy, 2005, 7 (4): 368-73.

20. Team co-headed by researchers at Chosun University, Seoul National University and the Seoul Cord Blood Bank (SCB) Umbilical cord cells 'allow paralysed woman to walk' By Roger Highfield, Science Editor. Last Updated: 1:28AM GMT 30 Nov 2004

21. Strauer BE, Schannwell CM, Brehm M. "Therapeutic potentials of stem cells in cardiac diseases". Minerva Cardioangiol , 2009, 57 (2): 249-67

22. Giarratana MC, Kobari L, Lapillonne H, et al. "Ex vivo generation of fully mature human red blood cells from hematopoietic stem cells". Nat. Biotechnol. 2005, 23 (1): 69-74.

23. Hair Cloning Nears Reality as Baldness Cure WebMD November 2004

24. Dental advance will let adults grow new teeth - Telegraph

25. Teeth from scratch

26. Yen AH, Sharpe PT. "Stem cells and tooth tissue engineering". Cell Tissue Res. 2008, 331 (1): 359-72

27. Gene therapy is first deafness 'cure' - health - 14 February 2005 - New Scientist

28. Fetal tissue restores lost sight MedicalNewsToday. Article Date: 28 Oct 2004 - 10:00 PDT

29. BBC NEWS | England | Southern Counties | Stem cells used to restore vision

30. The University Hospital of New Jersey, 2002

31. "Stem Cell Therapy Makes Cloudy Corneas Clear, According To Pitt Researchers". Medical News Today. 13 April 2009. http://www.medicalnewstoday.com/articles/145528.php. Retrieved 2009-06-04

32. Dr. Gearhart and Kerr of Johns Hopkins University. April 4, 2001 edition of JAM A (Vol. 285, 1691-1693)

33. Querida Anderson (2008-06-15). "Osiris Trumpets Its Adult Stem Cell Product". Genetic Engineering \& Biotechnology News (Mary Ann Liebert, Inc.): p. 13. http ://www.genengn ews.com/articles/chitem.asp x?aid=2508 . Retrieved 2008-07-06. "(subtitle) Procymal is being 
developed in many indications, GvHD being the most advanced.

34. Israeli scientists reverse brain birth defects using stem cells. December 25, 2008. (Researchers from the Hebrew University of Jerusalem-Hadassah Medical led by Prof. Joseph Yanai)

35. Centeno CJ, Busse D, Kisiday J, Keohan C, Freeman M, Karli D. "Regeneration of meniscus cartilage in a knee treated with percutaneously implanted autologous mesenchymal stem cells". Med. Hypotheses, 2008, 71 (6): 900-8. doi:10.1016/j. mehy.2008.06.042. PMID 18786777.

36. Centeno CJ, Busse D, Kisiday J, Keohan C, Freeman M, Karli D. "Increased knee cartilage volume in degenerative joint disease using percutaneously implanted, autologous mesenchymal stem cells". Pain Physician, 2008, 11 (3): 343-53.

PMID 18523506. http://www.painphy sicianjournal.com/linkout_vw.php?issn= $1533-3159 \&$ vol $=11 \&$ page $=343$.
37. Wakitani S, Nawata M, Tensho K, Okabe T, Machida H, Ohgushi H. "Repair of articular cartilage defects in the patello-femoral joint with autologous bone marrow mesenchymal cell transplantation: three case reports involving nine defects in five knees". J Tissue Eng Regen Med, 2007, 1 (1): 74-9.

38. Gurtner GC, Callaghan, MJ and Longaker MT. Progress and potential for regenerative medicine. Annu. Rev. Med, 2007, 58:299-312

39. Richards M, Fong CY, Bongso A. "Comparative evaluation of different in vitro systems that stimulate germ cell differentiation in human embryonic stem cells". Fertil. Steril. $\quad 2008, \quad 93 \quad$ (3): $986-94$. doi:10.1016/j.fertnstert.2008.10.030. PMID 19064262.

40. Sperm-like cells made from human embryonic stem cells Nature. Published online 7 July 2009. doi:10.1038/news.2009.646 